\title{
Espécies novas de Dianthidiini do Peru e Chile e nota taxonômica (Hymenoptera, Megachilidae) ${ }^{1}$
}

\author{
Danúncia Urban ${ }^{2}$
}

1 Contribuição número 1398 do Departamento de Zoologia, Universidade Federal do Paraná.

${ }^{2}$ Departamento de Zoologia, Universidade Federal do Paraná. Caixa Postal 19020, 81531-980 Curitiba, Paraná, Brasil. Bolsista do CNPq.

\begin{abstract}
New species of Dianthidiini from Peru and Chile and taxonomic note (Hymenoptera, Megachilidae). Two new species from Peru: Anthidulum lamasi sp. nov. from San Ramón and Anthidulum clausi sp. nov. from Pichanaki, both from the Junín Province; and Anthidianum chilense sp. nov. from Arica, Chile are described. The Lectotype of Anthidium caroliameghinoi Brèthes, 1903, is designated, and a taxonomic change is made: Antidianum caroliameghinoi (Brèthes, 1903) comb. nov.
\end{abstract}

KEY WORDS. Anthidulum, Anthidianum, Anthidiinae.

São conhecidas cinco espécies de Anthidulum Michener, 1948: A. currani (Schwarz, 1933), do Panamá, Zona do Canal e Colômbia, Magdalena; A christinae Urban, 1992, da Colômbia, Boyaca; e do Brasil: A cavichiolii Urban, 1992, de Mato Grosso; A. zanolae Urban, 1992, de Minas Gerais e São Paulo e A. mourei Urban, 1992, de São Paulo, Paraná e Argentina, Tucumán, Salta e Misiones; e duas espécies de Anthidianum Michener, 1948: A. subpetiolatum (Schrottky, 1910) ocorre na Bolívia, Oruro e Cochabamba e Argentina, Catamarca e Tucumán e, A. andicola Urban, 2001, na Argentina, Jujuy. Neste trabalho são descritas duas espécies de Anthidulum do Peru, cuja padronagem lembra a de Anthidulum mourei e, um novo Anthidianum do norte do Chile. O lectótipo de Anthidium caroliameghinoi Brèthes, 1903, é designado e uma combinação nova é proposta incluindo-o no gênero Anthidianum.

\section{Anthidulum lamasi sp. nov.}

Figs 1-2

Diagnose. Conhecido somente o macho, sem desenhos amarelos na área supraclipeal e com os mesepisternos pretos, genas pretas nos dois terços ventrais e somente os três tergos basais com larga margem preta, o terceiro com orla translúcida amarelo-pálida.

Holótipo macho. Comprimento aproximado 5,98 mm; comprimento da asa anterior a partir do esclerito costal 5,25 $\mathrm{mm}$; largura da cabeça 2,20 $\mathrm{mm}$. Tegumento predominantemente preto na cabeça e mesosoma, exceto as seguintes áreas amarelas: face externa das mandíbulas, o clípeo, este com o bordo enegrecido; máculas paroculares acompanhando o contorno do clípeo até as fóveas tentoriais, a partir daí estreitando um pouco em direção aos olhos e com a metade dorsal muito delgada, terminando ao nível do terço dorsal dos olhos; estria fina do terço dorsal das genas ao vértice, com pequena interrupção atrás do ocelo mediano. Antenas com o escapo amarelo-pálido, o pedicelo e demais flagelômeros ferrugíneos ventralmente; na face dorsal, o escapo castanhoenegrecido, o pedicelo e os três flagelômeros proximais ferrugíneos, os demais passando gradativamente a castanhoenegrecidos. Mesoscuto com máculas laterais amarelas finas em L invertido, as máculas terminando anteriormente à sutura escuto-escutelar; escutelo com orla amarela pouco mais larga que as máculas do mesoscuto, axilas com mancha arredondada amarela; tégulas castanho-enegrecidas, asas tingidas de castanho-escuro; pernas castanho-enegrecidas nos artículos basais inclusive nas coxas posteriores, passando a castanhas nos demais artículos, com mácula amarela muito pequena no ápice dos fêmures, as anteriores e medianas com a face anterior das tíbias e a externa dos basitarsos amarelas, a face ventral das tíbias amarelo-âmbar e os tarsômeros restantes ferrugíneos; as pernas posteriores com a tíbia preta, basitarso e o tarsômero proximal amarelos na face externa, os demais tarsômeros enegrecidos. Os três tergos basais pretos com áreas amarelas, o primeiro com faixas laterais amarelas muito largas, chegando ao bordo nos cantos, mais estreitas e mais basais no dorso e ai separadas por distância pouco maior que o diâmetro do ocelo; no segundo e terceiro tergos a faixa amarela larga, até o ápice nos flancos, no segundo ocupando aproximadamente um terço da largura do tergo e no terceiro mais larga ocupando a metade do tergo, neste com margem translúcida estreita amareloesbranquiçada; quarto e quinto amarelos com faixa preta estreita na base e a margem translúcida amarelo-âmbar; os dois tergos apicais amarelos. Esterno basal e base do segundo castanho-enegrecidos, os demais amarelo-pálidos. 
Holótipo macho. Peru, Junín: San Ramón (Rio Chanchamayo, $1400 \mathrm{~m}$ ), 27.VIII.1970, R. Garcia leg., no Museu de História Natural "Javier Prado", Universidad Nacional Mayor de San Marcos, Lima. Segundo G. Lamas coletado possivelmente nas montanhas, San Ramón está a 900 m de altitude.

Comentário. Pela chave de Urban (1992) esta espécie sairia juntamente com $A$. mourei, da qual difere pela área supraclipeal preta, estria amarela fina do terço dorsal das genas ao vértice e estrias amarelas também delgadas, em L invertido, nos flancos do mesoscuto; somente os dois tergos basais pretos na base e no ápice, o terceiro com faixas basal e subapical pretas e a margem translúcida amarelo-pálida. A. mourei tem três máculas amarelas na área supraclipeal, genas ferrugíneas ou com faixa amarela larga contínua com a do vértice, lados do mesoscuto com máculas amarelas largas em L invertido e, os quatro tergos basais predominantemente pretos com faixas discais amarelas inteiras ou interrompidas no meio.

Etimologia. Em homenagem ao Dr. Gerardo Lamas da Universidad Mayor de San Marcos, Lima, Peru.

\section{Anthidulum clausi sp. nov. Figs $3-4$}

Diagnose. Macho com três nódoas amarelas na área supraclipeal, estria fina amarela nas genas; mesepisternos com nódoa amarela; pernas com estrias amarelas; quarto ao sétimo tergo com margem translúcida esbranquiçada.

Holótipo macho. Comprimento aproximado 5,73 mm; comprimento da asa anterior a partir do esclerito costal $4,94 \mathrm{~mm}$; largura da cabeça $2,19 \mathrm{~mm}$. Tegumento preto com as seguintes áreas amarelas: face externa das mandíbulas, clípeo, mácula nas paroculares inferiores até as suturas subantenais, bruscamente estreitada nas proximidades dos alvéolos e com pequeno prolongamento dorsal muito delgado, a mácula ocupando os dois terços ventrais da face; três manchas na área supraclipeal, uma de forma triangular junto à sutura epistomal e duas em arco contornando os alvéolos medialmente; estria fina nas genas, mais estreita que a metade do diâmetro dos ocelos, das proximidades das mandíbulas até o vértice e com pequena interrupção atrás do ocelo mediano; mesoscuto com estrias laterais finas em L invertido, também estria fina no escutelo e nas axilas; pequena mancha na extremidade ventral dos lobos pronotais e nódoa arredondada na parte dorsal dos mesepisternos. Tégulas castanhas com área amarelada anterior, pouco conspícua. Pernas com os artículos basais pretos a castanhos, coxas posteriores com grande mácula amarela; os fêmures com mácula amarela longa, quase até a base, menos os posteriores com a mácula na metade apical; tíbias anteriores e medianas com estria amarelo-âmbar e as posteriores com duas máculas amarelas, a basal alongada e a apical arredondada; basitarsos anteriores amarelo-acastanhados, os medianos e posteriores amarelo-pálidos na face externa. Três tergos basais em grande parte pretos e sem margem translúcida clara, o primeiro com nódoas amarelas arredondadas nos flancos; segundo com faixa amarela estreita, ocupando aproximadamente um quarto do comprimento do tergo, mais basal dorsalmente e alargando muito nos lados; terceiro tergo com faixa amarela ocupando quase a metade do seu comprimento medialmente e quase todo o tergo nos flancos, com área subapical preta em arco e a margem translúcida amarelada; quarto ao sétimo tergo amarelos com área basal preta muito delgada e margem translúcida amarelo-esbranquiçada, mais estreita nos distais. Esternos amarelos, o primeiro preto com duas máculas amarelas triangulares.

Holótipo. Peru, Junín: Pichanaki, (Rio Chanchamayo, Perene), 11.VIII.1976, R. Garcia leg., no Museu de História Natural "Javier Prado", Universidad Nacional Mayor de San Marcos, Lima.

Comentário. Como a espécie anterior, na chave de URBAN (1992) A. clausi entraria junto com A. mourei, as duas têm em comum três máculas amarelas na área supraclipeal e os mesepisternos com mácula amarela ou amarelo-ferrugínea; $A$. mourei difere porque tem as genas inteiramente ferrugíneas ou com estria amarela larga, tégulas ferrugíneas e os quatro tergos basais com tegumento preto na base e no ápice.

Etimologia. Em homenagem ao M.Sc. Claus Rasmussen pelos seus estudos sobre as abelhas peruanas.

\section{Anthidianum chilense sp. nov.}

Allanthidium (Anthidianum) bizonatum; Toro \& Rodríguez, 1998: 66, figs $20-28$.

Toro \& Rodríguez (1998) identificaram e ilustraram (Figs 20 a 28) exemplares de Anthidianum, coletados em Putre, com máculas claras na face, que correspondem à espécie descrita neste trabalho. Tanto Anthidianum bizonatum (Friese, 1925) como A. subpetiolatum (Schrottky, 1910), foram dadas a conhecer pelo macho, caracterizado pelo colorido preto da face, ambas com duas faixas amarelas no metasoma. URBAN (2001) alocou Anthidianum bizonatum na sinonímia de Anthidianum subpetiolatum, e relacionou, por lapso, o Chile, na distribuição geográfica de A. subpetiolatum.

Diagnose. Mesoscuto preto, sem máculas amarelopálidas; metasoma com duas faixas amarelo-esbranquiçadas; macho com a metade ventral da cabeça amarelo-esbranquiçada e esculturação diferenciada no disco do clípeo: os pontos maiores que no restante do clípeo e separados por espaços lisos.

Holótipo macho. Comprimento aproximado $11 \mathrm{~mm}$, comprimento da asa $8,97 \mathrm{~mm}$, largura da cabeça $3,23 \mathrm{~mm}$. Cor predominante preta. Cabeça com clípeo, área supraclipeal e paroculares inferiores amarelo-esbranquiçadas, o clípeo com a margem preta, paroculares inferiores com a mácula amarela separada da base das mandíbulas por um espaço pouco maior que o ocelo e com o contorno dorsal irregular e alongado em direção às órbitas; vértice com máculas laterais em forma de meia-lua; antenas com os flagelômeros basais, escapo e pedicelo ferrugíneos, a partir do quarto flagelômero castanhas dorsalmente e no lado ventral castanho-ferrugíneas. Tégulas ferrugíneas, pernas com os artículos basais enegrecidos passando a ferrugíneas do ápice dos fêmures aos tarsos; asas bicoloridas, na metade basal tingidas de ferrugíneo e no restante, de castanho; veias ferrugíneas. Terceiro e quarto tergos com faixa discal amarela e os três tergos distais com o tegumento preto mesclado com castanho-avermelhado; esternos castanhoavermelhados.

Pilosidade predominante preta, densa e longa, porém castanho-pálida no escapo, artículos basais das pernas e mesepisternos, e ocre-amarelada sobre o tegumento ferrugíneo das pernas; clípeo denso-pontuado nos lados e na margem, com área discal marcada por pontos maiores que os restantes e separados por espaços lisos maiores que os pontos; supraclipeal 

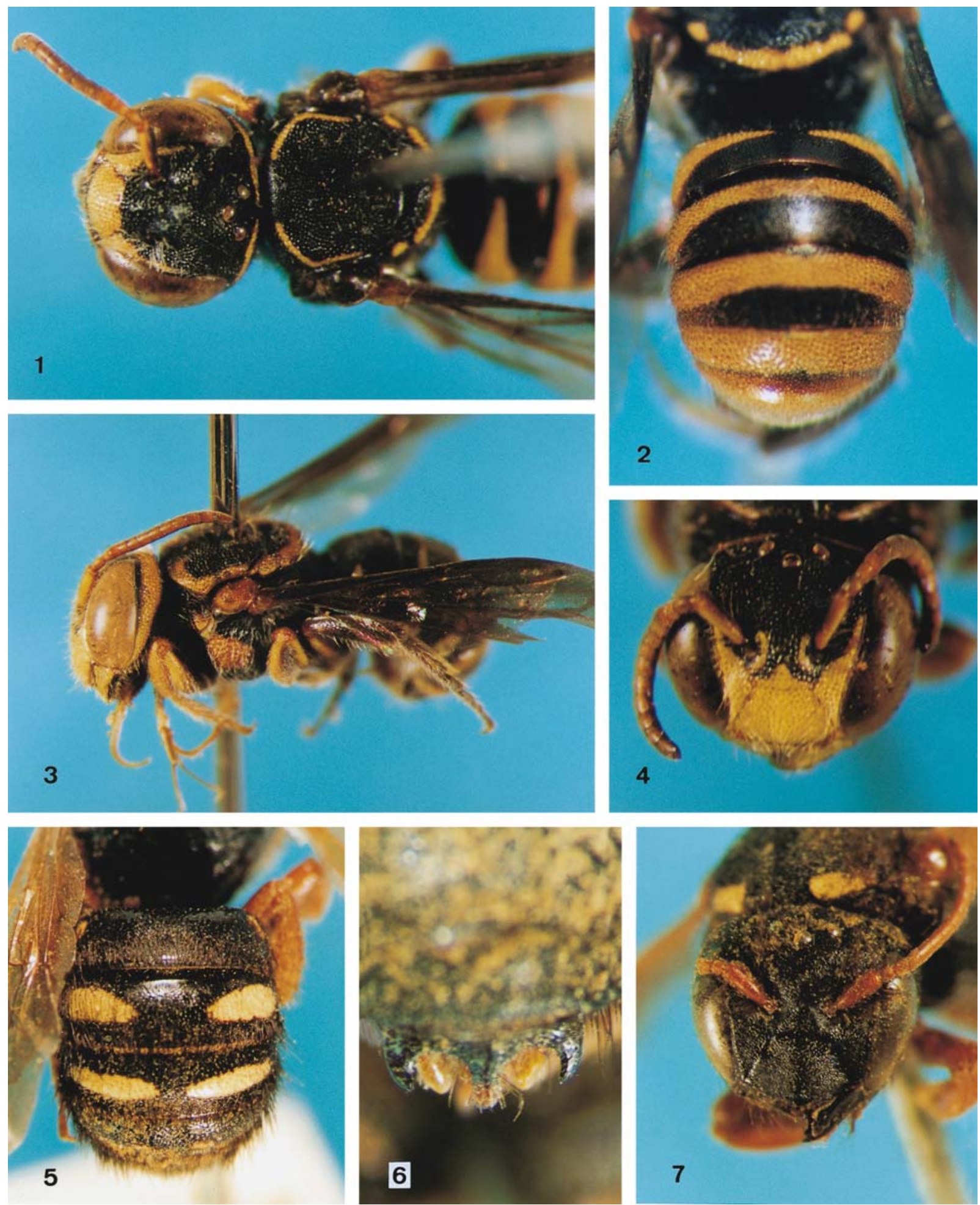

Figuras 1-7. (1-2) Anthidulum lamasi sp. nov.: (1) cabeça, mesosoma e tergos basais do holótipo macho, (2) escutelo e tergos do alótipo fêmea; (3-4) Anthidulum clausi sp. nov., holótipo macho: (3) perfil, (4) cabeça; (5-7) Anthidianum caroliameghinoi, lectótipo macho: (5) tergos basais, (6) tergos distais, (7) cabeça. 
sem pontos no disco, aos lados com pontos menores que os discais do clípeo; esterno basal com tubérculo alongado voltado para baixo, levemente arqueado e sub-truncado.

Fêmea. Comprimento aproximado $9,41 \mathrm{~mm}$; comprimento da asa anterior a partir do esclerito costal $8,77 \mathrm{~mm}$; largura da cabeça $3,38 \mathrm{~mm}$. Semelhante ao macho tanto no colorido do tegumento como da pilosidade, exceto a face preta; escopa marrom. Clípeo denso-pontuado com área estreita desprovida de pontos junto ao ramo transversal da sutura epistomal.

Distribuição geográfica. CHILE, Arica: Putre.

Holótipo macho. CHILE, Arica: Putre, 24-I-1948, [Kuschel leg.], na Coleção de Entomologia Pe. J.S. Moure, Departamento de Zoologia, Universidade Federal do Paraná (DZUP). Parátipos fêmeas da mesma localidade, coletados entre $3.000 \mathrm{~m}$ e $3.650 \mathrm{~m}$, no DZUP. plares.

Etimologia. Nome relativo ao país de origem dos exem-

Comentário. Anthidianum andicola Urban, 2001, tem três faixas amarelo-esbranquiçadas no metasoma e, tanto $A$. subpetiolatum como A. chilense têm duas faixas. A. subpetiolatum é caracterizado pelas faixas látero-basais amarelo-esbranquiçadas do mesoscuto; e, o macho, pela ausência de máculas amarelo-pálidas na face e pelo aspecto do clípeo com pontuação densa e grossa.

\section{Anthidianum caroliameghinoi (Brèthes, 1903) comb. nov.} Figs 5-7

Anthidium Caroli-Ameghinoi [sic] Brèthes, 1903: 351.

Dianthidium caroli-ameghinoi [sic]; Schrottky, 1913: 249.

O lectótipo macho de Anthidium caroliameghinoi, aqui designado, tem as seguintes etiquetas: 1) peças bucais coladas em um cartão; 2) cartão com o ${ }^{\circ}$ 6256; 3) Sta. Cruz; 4) etiqueta com friso verde: Caroli-Ameghinoi Bret / Patagonia, e no outro lado da etiqueta: Brethes / det / 1903; 5) etiqueta vermelha: Anthidium / caroliameghinoi / Brèthes, 1903 / cotype; 6) LECTÓTIPO / Urban desig., tendo no verso: 2002; 7) Anthidianum caroliameghinoi / (Brèthes, 1903) / Urban det. 2002, no Museu Nacional de Buenos Aires "Bernardino Rivadavia". A fêmea, paralectótipo, encontra-se no mesmo Museu.

Diagnose. Macho com a cabeça preta, incluindo o clípeo (Fig. 7), porém com duas pequenas nódoas amarelas nos cantos do vértice, segundo e terceiro tergos com um par de máculas amarelas (Fig. 5) e tergo distal com três projeções apicais alongadas (Fig. 6).

Lectótipo macho. Comprimento aproximado $8,82 \mathrm{~mm}$; comprimento da asa anterior a partir do esclerito costal $7,17 \mathrm{~mm}$, largura da cabeça $3 \mathrm{~mm}$. Tegumento preto predominando, exceto duas nódoas arredondadas amarelas nos cantos do vértice, faixas amarelo-pálidas nos flancos basais do mesoscuto (Fig. 7); um par de máculas alongadas ovóides no segundo e terceiro tergos (Fig. 5) e no quarto tergo máculas amarelas pequenas e irregulares. Antenas, tégulas e grande parte das pernas ferrugíneas, as pernas com enegrecido nas coxas, trocanteres e base dos fêmures. Asas com um banho de ferrugíneo na metade anterior, no restante tingidas de enegrecido.

Clípeo projetado para a frente e medianamente anguloso (Fig. 7), com dois lobos laterais fracos e pequena depressão subapical; sétimo tergo com três projeções apicais, duas laterais com a ponta voltada para o meio e para cima, e uma mediana um pouco mais longa que as laterais e voltada para trás (Fig. 6); primeiro esterno com tubérculo mediano largo e trapezoidal, segundo com carena baixa subapical e um pouco elevado aos lados, quinto e sexto esternos com formações espiniformes angulosas aos lados.

O revestimento piloso negro do espécimen a que se referiu BRÈTHES (1903) na descrição, está reduzido a pequenas áreas e colado com pequenos detritos.

Distribuição geográfica. Conhecido somente o materialtipo da Patagônia, Santa Cruz [Argentina].

Comentários. Esta espécie foi incluída no gênero Anthidianum pela aspecto peculiar do esterno basal do macho, com projeção mediana voltada para baixo, mais longa que a metade do comprimento do escapo e estreitando muito para os lados e, pela ausência de carena pré-episternal nos mesepisternos. Os machos de Anthidianum subpetiolatum, A. andicola e $A$. chilense têm em comum a margem mediana do clípeo em arco rebaixado, duas ou três faixas amarelo-esbranquiçadas no metasoma e o sétimo tergo ornado com quatro projeções digitiformes apicais; o macho de $A$. caroliameghinoi tem a margem do clípeo projetada em ângulo no meio, máculas amarelas aos lados no segundo e terceiro tergos e três projeções digitiformes no tergo distal.

\section{AGRADECIMENTOS}

Ao Dr. Gerardo Lamas do Museu de História Natural "Javier Prado" e ao M. Sc. Claus Rasmussen pelo empréstimo do material para estudo, ao Dr. Albino Morimasa Sakakibara do Departamento de Zoologia da Universidade Federal do Paraná pelas fotos que ilustram o trabalho e ao Dr. Arturo Roig Alsina do Museu Nacional de Buenos Aires "Bernardino Rivadavia" pelo empréstimo do síntipo de A. caroliameghinoi.

\section{REFERÊNCIAS BIBLIOGRÁFICAS}

BrÈthes, J. 1903. Un Nuevo Anthidium de Patagonia. Anales del Museo Nacional de Historia Natural de Buenos Aires, Buenos Aires, 9: 351-356.

Sснвоттку, C. 1913. La Distribución Geográfica de los Himenópteros Argentinos. Anales de la Sociedad Científica Argentina, Buenos Aires, 75: 115-144; 180-286.

Toro, H. \& S. Rodriguez 1998. Los Anthidiini de Chile: Clave para especies (Himenoptera: Megachilidae). Acta Entomológica Chilena, Santiago, 22: 63-78.

URBAN, D. 1992. Considerações sobre Anthidulum Michener, stat. n. e Dicranthidium Moure \& Urban, stat. n. e descrições de espécies novas (Hymenoptera, Megachilidae). Revista Brasileira de Zoologia, Curitiba, 9 (1/2): 11-28.

- 2001. Uma espécie nova de Anthidianum Michener e notas taxonômicas (Hymenoptera, Megachilidae). Revista Brasileira de Zoologia, Curitiba, 18 (1): 261-264.

Recebido em 11.XI.2002; aceito em 12.III.2003.

Revista Brasileira de Zoologia 20 (1): 127-130, março 2003 